\title{
Characterising Roof Fall Signatures from Underground Mines
}

\author{
A.T. lannacchione, L.M. Burke NIOSH, Pittsburgh Research Laboratory, USA \\ M.C. Chapman Virginia Technical University, USA
}

\begin{abstract}
A sequence of seismic events caused by multiple impacts of rocks of varying size hitting the mine floor and small rock rupturing events, associated with three roof falls, are analysed in terms of seismic moment, radiated seismic energy and apparent stress. The study site is an underground limestone quarry and the data were obtained from a multi-channel, in-mine seismic monitoring system. Estimates of seismic moment and radiated seismic energy are calibrated using rock drop tests and local quarry blasts. Experiments show that falling rocks are very inefficient sources of high frequency seismic energy, and that the condition of the mine floor (whether clear or debris-covered) plays a substantial role in determining the amount of radiated seismic energy. Massive (2,400 metric ton) roof falls differ from rock shear/rupture type events in that their signatures are emergent and long in duration, and they have a low apparent stress value. The low apparent stresses are thought to be caused by the inefficient source of roof rocks striking the mine floor. The observed moment magnitudes of four roof falls ranged from 0.1 to 1.4, with apparent stress less than other local mining induced seismic events. Prior to these massive roof failures, an increased level of seismic events associated with fracturing of the roof strata and ranging in magnitude from -1.4 to 0.3, are observed. The characteristic low apparent stress of the massive roof falls and precursory low-magnitude rock fracture events may hold promise for successful seismic monitoring of hazardous mine roof conditions.
\end{abstract}

\section{INTRODUCTION}

The act of extracting minerals from the earth creates a wide variety of seismic activity, most of short duration and relatively small amplitude. Research around the world has focused on rock bursts, catastrophic collapses, and seismicity associated with longwall coal mining. Much less attention has been given to lower energy roof fall events.

To understand how roof falls differ from other events it is necessary to examine the essential characteristics of each. Rock bursts are associated with a dynamic release of energy, typically ejecting rocks at high velocities from the ground immediately adjacent to the mine openings. Large rock bursts, the kind most often reported in the literature, generally are accompanied by strong seismic signatures that are associated with the initial release of energy. Catastrophic collapses, like those reported by Swanson and Boler (1995) and Ferriter et al. (1995) at the Solvay Mine and Phillips et al. (1997) at the White Pine Mine, occur when massive volumes of pillars that were probably under considerable strain suddenly fail. The strong seismic signatures associated with these events were reportedly due to the instantaneous failure of pillars and the associated implosion of the rockmass.

Large seismic events have also been observed in association with longwall coal mining. In the eastern U.S., the VP No. 3, Buchanan, and Lynch No. 37 Mines produced many large mining induced seismic events (Iannacchione and Zelanko, 1995). All three of these mines have massive strata that sometimes produce irregular gob caving cycles. Major events were traced back to either pillar bursts at the coalbed horizon or large strata movements along the boundaries of the cave zone. In several cases, the events were located hundreds of feet above the coalbed. In the western U.S., Ellenberger et al. (2001) located a magnitude 4.2 event 150 to $180 \mathrm{~m}$ above a deep cover longwall face with no associated bump observed underground. These events are probably similar to the events reported by Westbrook et al. (1980), Kusznir et al. (1984), and Redmayne (1988) in their studies of seismicity associated with longwall coal mining in the United Kingdom.

Roof falls, as defined in this study, are different from rock bursts and catastrophic collapses in that they are not characterized by a sudden, dynamic release of strain energy. The roof fall event itself is largely gravity driven. Typically, prior to falling, the roof strata has become highly fractured from past episodes of elevated stress levels or damaging deformation events and is often hanging tenuously from some overlying or adjacent rock layer. At some point, this connection is severed, probably by a tensile failure, allowing the loosely connected rockmass to fall to the floor. Seismic signatures are created as the broken rockmass strikes the floor. Roof falls differ from other events in the smaller size of their associated triggering event and the manner in which the rockmass strikes the ground. Unlike the massive, largely nonfractured strata associated with large catastrophic failures, the highly fractured roof fall mass comprises irregularly shaped blocks that strike the floor at slightly different times.

Mining induced seismicity recorded at the study site ranges in magnitude from slightly more than 2.0 to as low as -2.0 with rock fracture events associated with roof falls ranging from zero to -2.0 , the lower limit of detection capability. Determining the magnitude of these small mining induced events is complicated by inaccuracies in event location, complex source mechanisms, difficulty in determining $\mathrm{S}$ wave arrivals, and in the case of the roof falls, emergent, long-duration waveforms. To overcome these factors a combination of parameters defining the nature of the source is needed to characterize both roof fall and rock fracture seismic events encountered in the mining environment.

The approach taken here is to quantify event size using both the low frequency displacement spectral amplitude and the integral of the squared particle velocity, giving estimates of seismic moment and radiated seismic energy. 


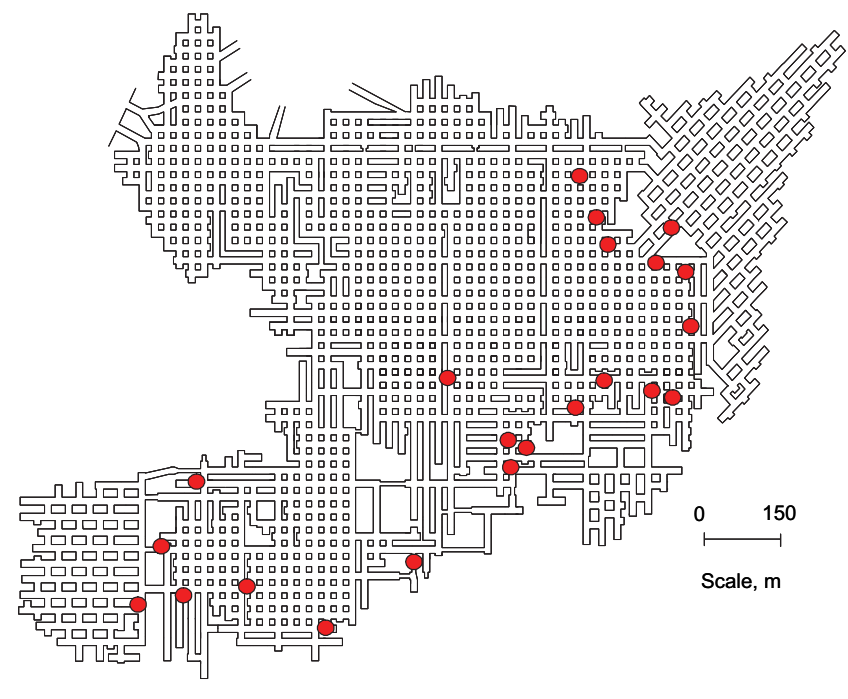

FIG. 1 Mine map of the Springfield Pike Quarry showing the locations of the seismic monitoring system geophones

The apparent stress is an important seismic source parameter that is derived from the ratio of radiated seismic energy and static seismic moment. This paper discusses the estimation of seismic moment, seismic energy and apparent stress for roof fall events and an important class of associated rock fracture events.

\section{THE STUDY SITE AND SEISMIC MONITORING SYSTEM}

The data for this analysis were collected at the Springfield Pike Quarry in southwestern Pennsylvania, an underground room-and-pillar operation mining the Loyalhanna Limestone. At the site, there are currently 22 Mark Products $4.5 \mathrm{~Hz}$ 630-ohm 3-component geophones used in a single component configuration (Figure 1). With one exception, the geophones are mounted on the roof some $8 \mathrm{~m}$ above the mine floor. One geophone was placed $21 \mathrm{~m}$ beneath the mine floor within a borehole.

Several hundred seismic events are recorded on a typical day at the Springfield Pike Mine. During the course of seismic monitoring at the study site, several thousand seismic events, including several roof falls, were recorded and located (Iannacchione et al., 2003). The largest events are the face blasts which involve approximately $410 \mathrm{~kg}$ of explosives that cast some $1.2 \times 10^{6} \mathrm{~kg}$ of rock into the adjacent entries. These events release significant elastic strain energy, producing clipped signal amplitudes for most of the closest geophones because of limited dynamic range. The largest events recorded by the array that could be assigned a magnitude emanated from adjacent quarry blasts. Intermediate in size are the larger rock falls. These events are recorded by most of the geophones throughout the mine. In general, the smallest events are associated with rock fracture, and are typically recorded only at the closest geophones. In addition, seismic emissions from scaling, drilling, and mucking operations are sometimes recorded, requiring additional examination and removal from the data base.

Typical rock fracture events have distinct first arrivals which allow the monitoring system to automatically identify the $P$ wave and then effectively locate the event in time and space. Roof fall events are not as well behaved. A single rock falling to the mine floor produces a signal with distinct body (P and S) and surface (Rayleigh and Love) wave arrivals. However, most roof falls contain numerous rocks of various sizes and shapes striking the ground at slightly different times. This results in complex wave signatures that are emergent and long in duration. Emergent waveforms lack a distinct $\mathrm{P}$ wave arrival and often are very difficult to locate. Direct observational information is used here to identify the time and location of roof fall events.

\section{DETERMINATION OF MAGNITUDE, SEISMIC MOMENT AND ENERGY}

Characterization of seismicity associated with roof falls requires quantification of event size in some sense. Short period local and regional earthquake magnitude scales based upon time domain measurements of peak amplitude are not well suited for this purpose because of the high frequencies and short source receiver distances encountered in the mining environment. Also, seismic events recorded in this study have variable source spectral shapes.

Routine measures provide insight into the variable duration of the seismic source and stresses involved with mining related events. Because the recorded spectra are not always representative of the typical $\omega^{-2}$ spectral shape usually associated with earthquakes, the estimation of a sourcerelated corner frequency is not always possible. Moreover, the estimation of stress drop in the context of a specific earthquake source model is not meaningful for some of the sources encountered in this study. The static seismic moment is proportional to the low frequency level of the displacement amplitude spectrum. The radiated energy is proportional to the integral of the particle velocity squared. The ratio of radiated energy to seismic moment is proportional to the apparent stress, a source parameter that is largely independent of source model. Together, seismic moment, radiated seismic energy and apparent stress provide a more complete description of the "size" and "intensity" of the seismic source than magnitude or seismic moment alone, and give some insight into stress release associated with various sources.

Moment magnitude, M (Hanks and Kanamori, 1979), is based on the static seismic moment, $\mathrm{M}_{\mathrm{o}}$ by the relationship:

$$
M=\frac{2}{3} \log \left(M_{o}\right)-6.0
$$

where $\mathrm{M}$ is expressed in SI units $(\mathrm{N}-\mathrm{m})$. The static seismic moment (Aki, 1968) is determined from the observed Fourier displacement amplitude spectrum of body waves according to

$$
M_{o}=\frac{4 \pi \rho c^{3} R\left|\Omega_{o}\right|}{F_{c}}
$$

where:

$\Omega_{\mathrm{o}}$ is the low frequency spectral plateau of the displacement spectrum determined for $\mathrm{P}$ or $\mathrm{S}$ wave, $(\mathrm{m} / \mathrm{Hz})$,

$\rho$ is the density at the source $\left(\mathrm{kg} / \mathrm{m}^{3}\right)$,

C is the P wave or $S$ wave velocity $(\mathrm{m} / \mathrm{s})$,

$\mathrm{F}_{c}$ is the $\mathrm{P}$ wave or $\mathrm{S}$ wave radiation pattern coefficient for source and receiver, and

$\mathrm{R}$ is the distance between the seismic source and the receiver $(\mathrm{m})$.

The radiated seismic energy, $\mathrm{E}_{\mathrm{s}}$ (Boatwright and Fletcher, 1984), is given by:

$$
E_{s}=4 \pi \rho c R^{2}<F_{c}>^{2} F_{c}^{-2}\left(I_{z}+I_{H 1}+I_{H 2}\right)
$$

where:

$<\mathrm{FC}>$ is the root-mean-square (RMS) radiation pattern coefficient for $\mathrm{P}$ or $\mathrm{S}$ waves,

$\mathrm{I}_{\mathrm{z}^{\prime}} \mathrm{I}_{\mathrm{H} 1}$ and $\mathrm{I}_{\mathrm{H} 2}$ are the integrals of the squared velocity for the vertical $(\mathrm{Z})$ and two horizontal $(\mathrm{H} 1, \mathrm{H} 2)$ components of $\mathrm{P}$ or $\mathrm{S}$ wave motion. 
Complex, mostly gravity driven events such as roof falls are difficult to quantify in terms of size, and estimates of seismic moment, seismic energy and apparent stress are particularly useful for characterizing such events.

\section{P AND S WAVE VELOCITIES AND RADIATION COEFFICIENT}

$P$ and $S$ wave velocities for all microseismic events emanating from the roof of the Loyalhanna Limestone are determined directly from the known locations of underground face blasts. P wave velocities range from 4570 to $5334 \mathrm{~m} / \mathrm{s}$ and average $5029 \mathrm{~m} / \mathrm{s}$, while $S$ wave velocities average $3370 \mathrm{~m} / \mathrm{s}$. The P wave velocity for Loyalhanna Limestone floor strata, determined from rock drop tests, averages $4633 \mathrm{~m} / \mathrm{s}$ with a corresponding $S$ wave velocity average of $2574 \mathrm{~m} / \mathrm{s}$. The $\mathrm{P}$ and $\mathrm{S}$ wave velocities for blasts occurring from adjacent quarry operations are determined from measured blast times and locations. $\mathrm{P}$ wave velocities for adjacent quarry blasts range from 6510 to $4635 \mathrm{~m} / \mathrm{s}$ while $\mathrm{S}$ wave velocities range from 3617 to $2576 \mathrm{~m} / \mathrm{s}$ with an average of $3039 \mathrm{~m} / \mathrm{s}$.

The radiation pattern coefficient, $\mathrm{F}_{\mathrm{c}^{\prime}}$ accounts for the directionally dependent amplitude and polarity of $\mathrm{P}$ and $\mathrm{S}$ waves from the various force systems associated with seismic sources. For example, in the case of the double couple system viable for most earthquakes, the radiation pattern can be expressed as a function of the fault strike, dip, direction of slip, azimuth from source to receiver, and ray take-off angle at the source, given a focal mechanism solution or moment tensor inversion. Determining the values of $F$ in equations [2] and [3] is not possible with the existing data for this study because only a single horizontal component of ground motion is recorded at each receiver location. For calculation of seismic moment, we represent the unknown radiation pattern coefficient of all events studied here as the RMS values for double-couple sources. Boore and Boatwright (1984) find RMS values of 0.52 for $P$ waves and 0.63 for $S$ waves. Those values are used in this study for rock fracture events.

\section{SPECTRAL MEASUREMENTS OF SEISMIC MOMENT AND RADIATED SEISMIC ENERGY}

The low frequency asymptote $\Omega_{\mathrm{o}}$ was estimated from the Fourier amplitude spectrum of ground displacement. $\Omega$ is estimated for the entire signal signature and the $S$ wave velocity, using at least 1024 sample points, at a sample rate of 1929 samples per second for all signals except the December 4, 2003 roof fall (992 samples per second). The bandwidth of the data used to estimate $\Omega_{0}$ with acceptable signal to noise ratio is approximately $6 \mathrm{~Hz}$ to $30 \mathrm{~Hz}$ for most events. The exception to this are the roof falls and quarry blast events where much of the energy is contained in the 1 to $20 \mathrm{~Hz}$ range. The natural frequency of the velocity transducers is 4 $\mathrm{Hz}$. In addition, a $250 \mathrm{~Hz}$ low-pass corner frequency is part of the recording system. In most cases, instrument response correction amounted to accounting for the system response to ground velocity of 2118 digital counts per $\mu \mathrm{m} / \mathrm{sec}$ for frequencies greater than $4 \mathrm{~Hz}$. Ideally, the estimate of $\Omega_{\mathrm{o}}$ would be based on the square root of the sum of squares from the three components of motion. Equal amplitude is assumed on all three components, and accordingly $\Omega$ is estimated by multiplication of the single component measurements by a factor of 1.73 .

The integral of squared velocity was computed in the frequency domain by performing a full recording system response correction to ground velocity, squaring the result and integrating over the frequency band with acceptable signal to noise ratio. The band of acceptable signal to noise ratio is determined for each signal by visual inspection of pre-P wave noise in time windows equal in duration to those of the signal. A signal-to-noise ratio of three is deemed acceptable. Equal amplitudes are again assumed on the three components, and the single component estimate is multiplied by three, producing an estimate of seismic energy according to equation 3.

\section{THE DATA}

In addition to the roof fall events and associated rock fracture events of primary interest, data from a series of rock drop tests and local blasts are examined. The rock drop tests are important because they give insight to the efficiency of the roof fall source in converting kinetic energy into seismic energy by providing impulsive sources with known kinetic energies at known locations. Both rock drops and local blasts provide data to determine site-specific estimates of $P$ and $S$ wave velocities used to calculate seismic moment and radiated seismic energy.

\section{ROCK DROP TESTS}

Eight rock drop tests were evaluated on three different mine floor foundations: clean solid rock, broken rock, and fines and rock fragments (Table 1). The rocks were dropped from a front-end loader extended to height of approximately 5 $\mathrm{m}$. The kinetic energy of the rocks at time of impact with the floor ranged from $1.8 \times 10^{5}$ to $8.8 \times 10^{5} \mathrm{~J}$. Rocks that fell on 41 to $76 \mathrm{~cm}$ layers of broken rocks and fines (Table 1) did not transfer enough energy into the floor rock to produce detectable seismic waves. The importance of this observation is discussed below. Figure 2 shows a picture of one of these tests.

\section{TABLE 1 Characteristics of 8 rock drop tests}

\begin{tabular}{lllll}
\hline $\begin{array}{l}\text { Test } \\
\text { metric } \\
\text { tons, } \mathbf{t}\end{array}$ & $\begin{array}{l}\text { Mass, } \\
\mathbf{N}\end{array}$ & $\begin{array}{l}\text { Kinetic } \\
\text { Energy, } \\
\mathbf{J}\end{array}$ & Surface Condition \\
\hline 1 & 17.9 & $1.8 \times 10^{5}$ & $8.8 \times 10^{5}$ & Clean \\
2 & 3.7 & $3.7 \times 10^{4}$ & $1.8 \times 10^{5}$ & Clean \\
3 & 8.3 & $8.2 \times 10^{4}$ & $4.1 \times 10^{5}$ & Clean \\
4 & 13.8 & $1.3 \times 10^{5}$ & $6.7 \times 10^{5}$ & Clean \\
5 & 5.9 & $5.8 \times 10^{4}$ & $2.9 \times 10^{5}$ & $61 \mathrm{~cm}$ of broken rock \\
6 & 8.3 & $8.2 \times 10^{4}$ & $4.1 \times 10^{5}$ & $41 \mathrm{~cm}$ of fines \\
7 & 8.3 & $8.2 \times 10^{4}$ & $4.1 \times 10^{5}$ & $76 \mathrm{~cm}$ of fines \\
8 & 8.3 & $8.2 \times 10^{4}$ & $4.1 \times 10^{5}$ & Clean \\
\hline
\end{tabular}

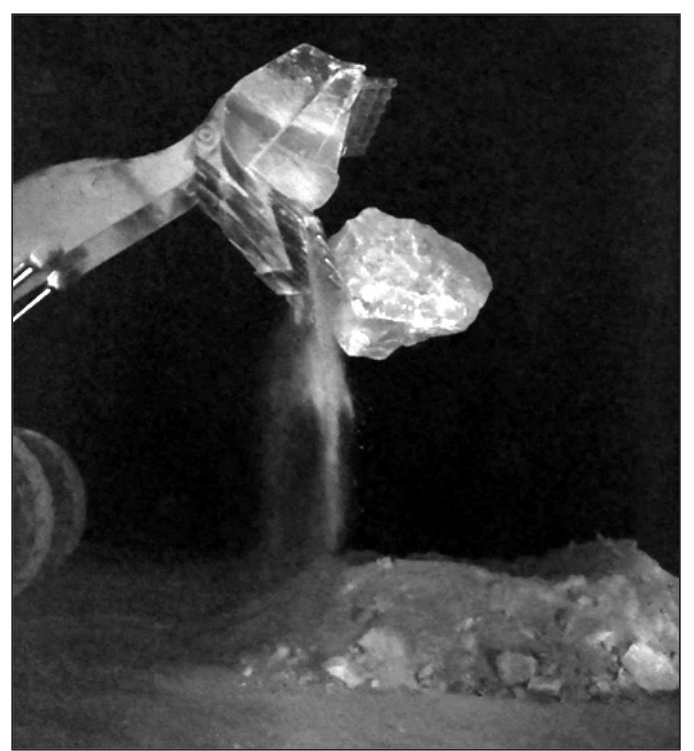

FIG. 2 Photograph of a rock drop test showing a $8.3 \times 10^{3} \mathrm{~kg}$ rock dropping onto a pile of fines and broken rock 
Five rocks were dropped onto a solid limestone floor, clear of any appreciable fines or broken rock material. In these tests, sufficient coupling occurred between the rock and ground to produce strong signals. Moment magnitude and energy calculations used the velocities determined directly from the rock drop tests. Table 2 shows the moment magnitude values calculated from the $\mathrm{S}$ wave properties, along with estimates of radiated seismic energy for signal/noise ratios greater than three and over a very wide frequency band.

Figure 3 shows the waveforms recorded by geophone 15 from all five rock drop tests. Note the clear P wave arrivals with higher frequency waves followed by lower frequency shear and/or surface waves. Figure 4 shows the corresponding Fourier displacement amplitude spectra for drop tests 1 and 8 .
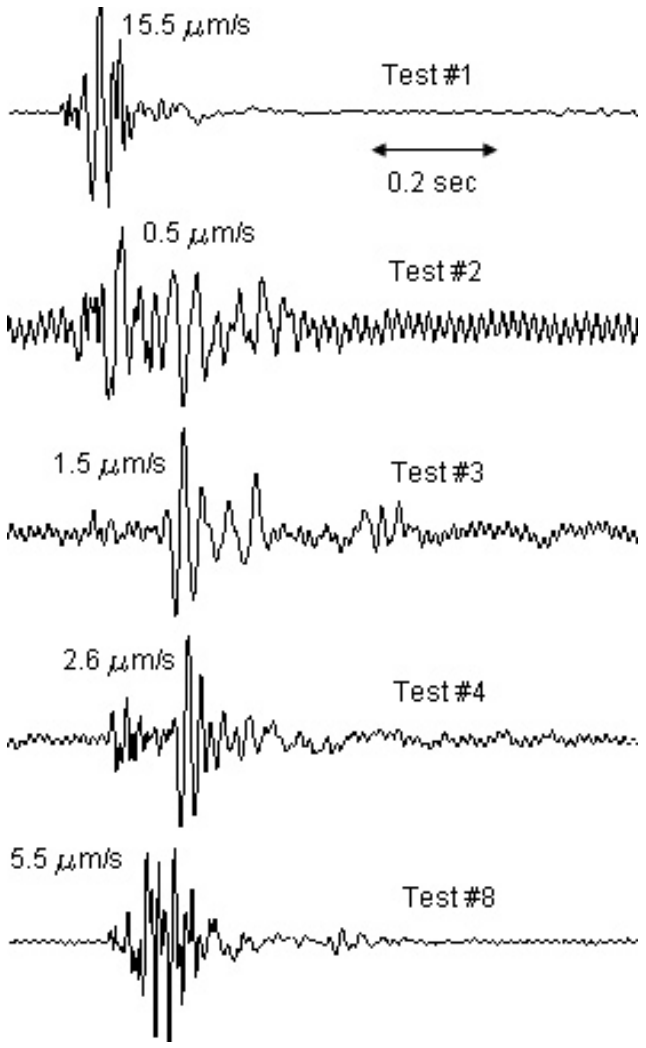

FIG. 3 Signals recorded by geophone 15 from five rock drop tests. Peak velocities are indicated

Data from geophone 15 were selected for calculating energy estimates for the five drop tests because that geophone is placed within a borehole $21 \mathrm{~m}$ into the floor, reducing the effects of vibrations from fans and vehicle traffic. All other geophones of the microseismic network are attached to the mine roof and, therefore, are not as effectively coupled to the rock impacts upon the floor. The moment magnitudes recorded by geophone 15 ranged from 0.0 for the $1.8 \times 10^{4} \mathrm{~kg}$ rock to -1.9 for the $3.7 \times 10^{3} \mathrm{~kg}$ rock (Figure 5).

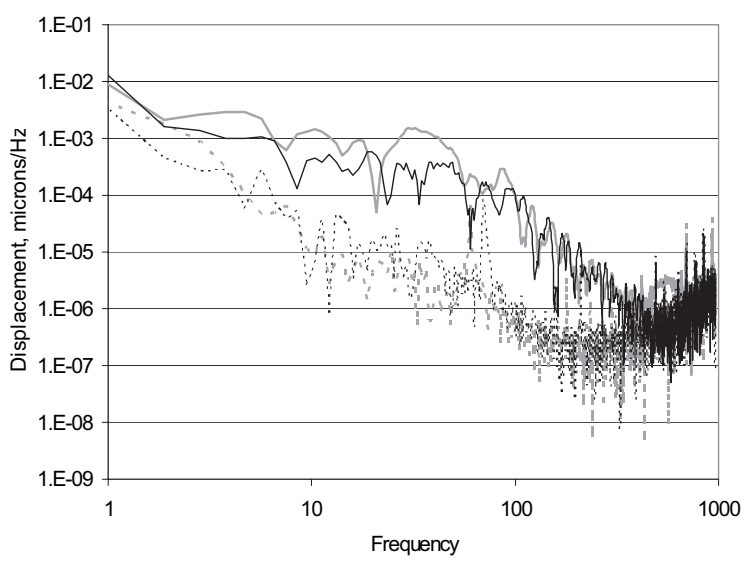

- Test\#1, background noise —— Test\#1, drop test

Test\#8, background noise —_ Test\#8, drop test

FIG. 4 Fourier displacement amplitude spectra for rock drop tests \#1 and \#8, recorded by geophone 15. Pre-P wave noise levels are indicated by the thin, dashed lines. The straight line indicates an $\omega-2$ spectral slope

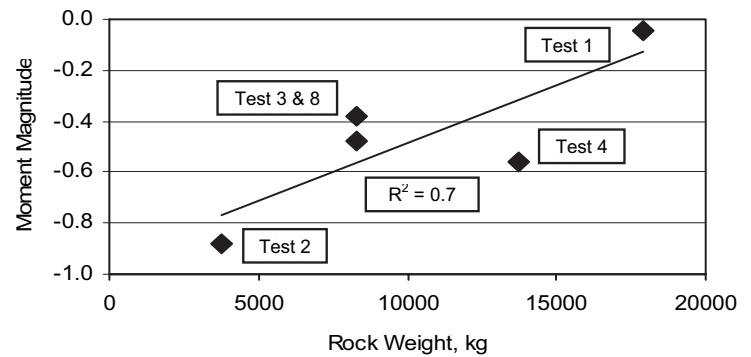

FIG. 5 Moment magnitude versus rock weight for the five drop tests

The five rocks that were dropped on the clean mine floor produced sufficiently large signal to noise ratios and signal bandwidth at geophone location 15 to permit a determination of radiated seismic energy. The relationship between seismic moment and energy for these two single rock impacts is examined, to gain insight into the scaling relationships for more complex roof fall events. Bandwidths between 2 to $400 \mathrm{~Hz}$ for radiated seismic energy with a signal-to-noise ratio of greater than three are used to calculate these values. Source-receiver distances ranged from 266 to $737 \mathrm{~m}$ (Table 2 ), so geometrical spreading differences between the events are negligible. The instrument-corrected spectra are well represented by the $\omega^{-2}$ shape, with corner frequencies in the 30 to $60 \mathrm{~Hz}$ range (Figure 4). No corrections for anelastic attenuation or scattering were applied, and body wave spreading was assumed.

The velocity squared integrals were calculated by assuming a constant displacement amplitude level from 0.5

TABLE 2 Microseismic properties of rock drop tests

\begin{tabular}{|c|c|c|c|c|c|c|c|c|c|c|}
\hline $\begin{array}{l}\text { Test } \\
\text { number }\end{array}$ & $\begin{array}{l}\text { S wave } \\
\text { velocity, } \mathrm{m} / \mathrm{s}\end{array}$ & $\begin{array}{l}\text { Distance, } \\
\text { m }\end{array}$ & $\Omega_{\mathrm{o}}, \mathrm{m} / \mathrm{Hz}$ & $\mathrm{Hz}$ range & $M_{o}, N-m$ & MM & $E_{s}$, Joules & $\mathrm{Hz}$ range & $\tau_{\mathrm{a}}, \mathrm{MPa}$ & $\begin{array}{l}\text { Duration, } \\
\mathrm{s}\end{array}$ \\
\hline 1 & 2963 & 266 & $2.1 \times 10^{-9}$ & 5.7 to 400 & $8.6 \times 10^{8}$ & 0.0 & 93.1 & 1.9 to 400 & $1.8 \times 10^{-3}$ & 0.34 \\
\hline 2 & 2963 & 266 & $1.2 \times 10^{-10}$ & 6.6 to 184 & $4.8 \times 10^{7}$ & -0.9 & 0.2 & 2.8 to 185 & $6.0 \times 10^{-5}$ & 0.42 \\
\hline 3 & 2506 & 737 & $4.0 \times 10^{-10}$ & 7.3 to 101 & $2.7 \times 10^{8}$ & -0.4 & 8.8 & 2.4 to 101 & $5.4 \times 10^{-4}$ & 0.73 \\
\hline 4 & 2320 & 628 & $3.2 \times 10^{-10}$ & 17 to 359 & $1.5 \times 10^{8}$ & -0.6 & 12.9 & 17 to 259 & $1.5 \times 10^{-3}$ & 0.59 \\
\hline 8 & 2506 & 266 & $8.0 \times 10^{-10}$ & 6.5 to 400 & $1.9 \times 10^{8}$ & -0.5 & 15.8 & 7.3 to 400 & $1.4 \times 10^{-3}$ & 0.63 \\
\hline
\end{tabular}


$\mathrm{Hz}$ to the lower limit of the signal band. Likewise, $\omega^{-2}$ decay of displacement spectral amplitude was assumed between the upper frequency limit of the signal band and the Nyquist frequency $(964 \mathrm{~Hz})$. The energy estimates are not sensitive to assumed behaviour of the spectra outside the band of good signal to noise ratio for the drop tests. The integral of velocity squared is dominated by the portion of the spectrum in the vicinity of the corner frequency.

The quantity $<\mathrm{Fc}>/ \mathrm{Fc}_{\mathrm{C}}$ in equation 3 is assumed to be unity for all the energy calculations. This choice for the radiation pattern is unconstrained by observation, but insofar as we are interested in resolving gross, order-of-magnitude aspects of the recorded data, this choice is of secondary importance. A more important experimental difficulty associated with the energy estimation involves the time windows chosen for spectral analysis and the different seismic phases arriving within these small time windows. Based on a study of events showing separation of $\mathrm{P}$ and $\mathrm{S}$ arrivals, it appears that the portion of the time series corresponding to direct $S$ and later arrivals carries most of the energy, and that the contribution from the $\mathrm{P}$ wave is insignificant. However, this is based on horizontal component observations. Also, the $\mathrm{S}$ wave arrival is not impulsive, implying that a significant amount of radiated energy on the horizontal components is in the form of highly scattered S waves and/or surface waves. These complications may result in substantial error because spherical spreading is assumed for body waves as indicated in equation [3]. Unfortunately, it is not possible to assess these complications with the single component data set. Rather, a simple approach is taken in which the entire time series is windowed beginning prior to the onset of the $\mathrm{P}$ wave and including that portion of the $S$ wave coda with significant amplitude. In the case of the rock drop tests shown in figure 3 , the window was 0.5 seconds. A trapezoidal taper is applied at the final $10 \%$ of the window to reduce the amplitudes of side-lobes in the frequency domain. The shear wave velocity in the limestone floor ranges from 2320 to $2963 \mathrm{~m} / \mathrm{s}$ with an assumed density of $2643 \mathrm{~kg} / \mathrm{m}^{3}$ (Table 2). These value are used in equation 3 to determine the seismic energy of the rock drop tests because most of the energy appears to be associated with that phase.

Estimates of the radiated seismic energy for the drop tests range from 0.2 to $93.1 \mathrm{~J}$ (Table 2). Regardless of the large uncertainties in the measurements, the radiated seismic energy is very small compared to the translational kinetic energy of the impacting rocks. The estimated ratios of radiated seismic energy to kinetic energy are $1.1 \times 10^{-4}$ and $3.9 \times 10^{-5}$ for tests 1 and 8 , respectively. Whereas the kinetic energy of test 1 exceeds that of test 8 by a factor of 2.8 , the seismic energy of test 1 exceeds that of test 8 by a factor of 5.9 . This indicates a complex mechanism for conversion of kinetic energy to seismic energy in these simple tests. The ratios of seismic energy to seismic moment of the two drop tests are in closer agreement: $1.1 \times 10^{-7}$ (test 1 ) and $8.3 \times 10^{-8}$ (test 8 ). The spectra shown in figure 4 have similar corner frequencies and almost equal amplitudes at frequencies between 100 and 400 Hz. Test 1 was more energetic at lower frequencies, resulting in both a larger estimate of seismic moment and a higher value of seismic energy. by:

The apparent stress, $\tau$, defined by Wyss (1970) is given

$$
\tau_{\mathrm{a}}=\mathrm{G} \cdot\left(\mathrm{E}_{\mathrm{s}} / \mathrm{M}_{\mathrm{o}}\right)
$$

where: $\mathrm{G}$ is the modulus of rigidity, $\mathrm{Pa}$.

Apparent stress is assumed to be a measure of stresses operating during earthquake shear dislocation events and is useful in this study because it is assumed to be independent of a source model. However, the interpretation of apparent stress estimates derived from seismic measurements depends on the source model. In the case of the drop tests, the source does not involve shear tractions on a fault surface, and $\tau_{\text {a }}$ does not represent the magnitudes of stresses actually involved in these impacts. However, the exercise of estimating $\tau_{\mathrm{a}}$ is useful because the parameter is simply related to the gross spectral character through the ratio of the integrated spectrum of ground velocity squared to the low frequency displacement amplitude level. For example, displacement spectra with larger than average zero frequency levels and/or lower than average corner frequencies have lower than average apparent stress.

On the basis of the $S$ wave velocity measurements a value of $1.65 \times 10^{4} \mathrm{MPa}$ is assumed for $\mathrm{G}$ and $\tau$ ranges from $6.0 \times 10^{-5}$ to $1.8 \times 10^{-3} \mathrm{MPa}$. McGarr (1999) summarizes measurements of apparent stress for mining induced earthquakes, laboratory stick-slip friction events, earthquakes triggered by liquid injection, and small earthquakes recorded in deep boreholes in California. The drop test sources are mechanically very different from the shear dislocations in continuous media examined by McGarr (1999). The apparent stresses found here are near or below the lower limit of the range observed for those other types of seismic source. Note that these results apply only to impacts on a clean, hard-rock floor, recorded by a horizontal component geophone within the floor. Also, the ratio of seismic energy to kinetic energy, as well as the ratio $\mathrm{E}_{\mathrm{s}} / \mathrm{M}_{\mathrm{o}}$, should depend upon the velocity of impact. The velocities in the rock drop tests are small, approximately 10 $\mathrm{m} / \mathrm{sec}$, and are not sufficient to cause the impacting rock to shatter. The apparent stress and the ratio of seismic energy to kinetic energy may decrease when impact stresses begin to exceed the rock strength, causing fragmentation. This may, in fact, cause an upper limit to the apparent stress for these types of low speed impacts.

\section{QUARRY BLASTS}

The Springfield Pike underground quarry is located in a major limestone producing district of Western Pennsylvania (Iannacchione et al., 2002). Within $30 \mathrm{~km}$ of this site, four large quarries operate a combination of surface and underground mines. These quarries blast rock faces ranging from 14 to almost $100 \mathrm{~m}$ in length several times a week, usually on regular intervals. During a two month period between March and April of 2002, information on the timing, size, and location of blasts were collected from the surrounding quarries and compared to data records from the Springfield Pike seismic monitoring system. Typically, the underground blasts are small, averaging approximately $658 \mathrm{~kg}$ of ANFO per blast while surface blasts are quite large, ranging from 3,994 to $26,053 \mathrm{~kg}$ of ANFO per blast.

Distinguishing blasts from other seismic phenomena associated with mining operations is sometimes difficult. Recorded signals from blasts in the Springfield Pike underground quarry at distances less than $2 \mathrm{~km}$ from the monitoring equipment are often clipped. Locating these events is challenging because the $P$ and $S$ waves are virtually indistinguishable on clipped recordings. Blasts at distances greater than $10 \mathrm{~km}$ typically lack clear $\mathrm{P}$ wave arrivals, due to delay firing, and the automatic detection algorithm of the monitoring system often triggers on the stronger $\mathrm{S}$ arrival, missing the $\mathrm{P}$ wave arrival and interval between $\mathrm{P}$ and $\mathrm{S}$. During a two month study, many blasts signals were recorded from the Coolsprings, Rich Hill, and Jim Mountain Quarries and their properties were calculated (Table 3). Figure 6 shows a general increase in blast magnitude with increases in the total weight of explosives.

Figure 7 shows the waveforms and displacement amplitude spectra from a blast at the Rich Hill quarry, approximately $5.2 \mathrm{~km}$ from the monitoring array with a total explosive 
TABLE 3 Microseismic properties of blasts from nearby quarries

\begin{tabular}{|c|c|c|c|c|c|c|c|c|c|c|}
\hline Quarry name & $\begin{array}{l}\text { Distance, } \\
\text { m }\end{array}$ & $\Omega_{o}, \mathrm{~m} / \mathrm{Hz}$ & $\mathrm{Hz}$ range & $M_{0}, N-m$ & MM & $E_{s}$, Joules & $\mathrm{Hz}$ range & $\tau_{\mathrm{a}}, \mathrm{MPa}$ & $\begin{array}{l}\text { Explosive } \\
\text { Wt., kg }\end{array}$ & Duration, $\mathbf{s}$ \\
\hline Jim Mountain & 13,543 & $5.8 \times 10^{-7}$ & 0.5 to 13 & $2.8 \times 10^{12}$ & 2.3 & $1.8 \times 10^{6}$ & 0.5 to 13 & $1.0 \times 10^{-2}$ & 17,474 & 7 \\
\hline Jim Mountain & 13,543 & $1.2 \times 10^{-7}$ & 0.5 to 11 & $5.7 \times 10^{11}$ & 1.8 & $1.0 \times 10^{5}$ & 0.5 to 11 & $2.9 \times 10^{-3}$ & 2,758 & 4 \\
\hline Jim Mountain & 13,543 & $2.6 \times 10^{-7}$ & 0.5 to 58 & $1.3 \times 10^{12}$ & 2.1 & $3.7 \times 10^{5}$ & 0.5 to 58 & $4.8 \times 10^{-3}$ & 7,911 & 5.5 \\
\hline Jim Mountain & 13,543 & $5.3 \times 10^{-7}$ & 0.5 to 15 & $2.6 \times 10^{12}$ & 2.3 & $1.9 \times 10^{6}$ & 0.5 to 15 & $1.2 \times 10^{-2}$ & 14,980 & 5 \\
\hline Rich Hill & 5,242 & $1.6 \times 10^{-6}$ & 0.5 to 51 & $7.6 \times 10^{12}$ & 2.6 & $1.2 \times 10^{6}$ & 0.5 to 51 & $2.6 \times 10^{-3}$ & 26,053 & 5 \\
\hline Rich Hill & 5,242 & $2.1 \times 10^{-7}$ & 0.5 to 52 & $1.0 \times 10^{12}$ & 2.0 & $5.5 \times 10^{4}$ & 0.5 to 52 & $8.8 \times 10^{-4}$ & 3,994 & 6 \\
\hline Rich Hill & 5,242 & $3.5 \times 10^{-7}$ & 0.5 to 50 & $1.7 \times 10^{12}$ & 2.2 & $8.0 \times 10^{4}$ & 0.5 to 50 & $7.7 \times 10^{-4}$ & 6,259 & 6 \\
\hline Rich Hill & 5,242 & $4.9 \times 10^{-7}$ & 0.5 to 53 & $2.4 \times 10^{12}$ & 2.3 & $3.5 \times 10^{5}$ & 0.5 to 53 & $2.4 \times 10^{-3}$ & 21,847 & 8 \\
\hline Rich Hill & 5,242 & $4.6 \times 10^{-7}$ & 0.5 to 74 & $2.2 \times 10^{12}$ & 2.2 & $2.3 \times 10^{5}$ & 0.5 to 74 & $1.6 \times 10^{-3}$ & 21,847 & 3 \\
\hline Rich Hill & 5,242 & $6.5 \times 10^{-7}$ & 0.5 to 53 & $3.2 \times 10^{12}$ & 2.3 & $5.7 \times 10^{5}$ & 0.5 to 53 & $3.0 \times 10^{-3}$ & 6,084 & 5.5 \\
\hline Rich Hill & 5,242 & $5.6 \times 10^{-7}$ & 0.5 to 58 & $2.7 \times 10^{12}$ & 2.3 & $2.2 \times 10^{5}$ & 0.5 to 58 & $1.3 \times 10^{-3}$ & 12,081 & 4 \\
\hline Coolsprings & 14,300 & $3.6 \times 10^{-9}$ & 2.8 to 48 & $8.3 \times 10^{10}$ & 1.3 & $1.7 \times 10^{4}$ & 2.8 to 48 & $3.3 \times 10^{-3}$ & 658 & 1.5 \\
\hline Coolsprings & 14,300 & $2.7 \times 10^{-9}$ & 3.3 to 48 & $6.1 \times 10^{10}$ & 1.2 & $8.5 \times 10^{3}$ & 3.3 to 49 & $2.3 \times 10^{-3}$ & 658 & 1.5 \\
\hline Coolsprings & 14,300 & $1.6 \times 10^{-9}$ & 2.8 to 48 & $3.7 \times 10^{10}$ & 1.1 & $3.1 \times 10^{3}$ & 2.8 to 49 & $1.4 \times 10^{-3}$ & 658 & 1.5 \\
\hline
\end{tabular}

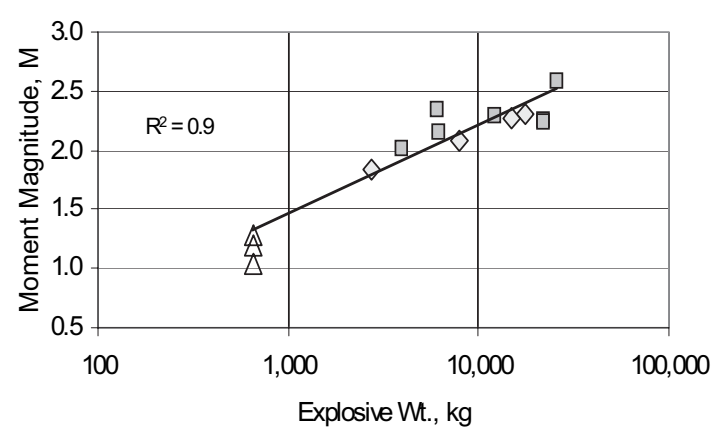

$\diamond \operatorname{Jim}$ Mountain $\square$ Rich Hill $\triangle$ Coolsprings

FIG. 6 Moment Magnitude versus total explosive load for several blasts from three local quarries

weight of $21,847 \mathrm{~kg}$. The signal-to-noise ratio is greater than three in the range of frequencies from 0.5 to $53 \mathrm{~Hz}$. The seismic moments is estimated to be $2.4 \times 10^{12} \mathrm{~N}-\mathrm{m}$ with a radiated seismic energy of $3.5 \times 10^{5} \mathrm{~J}$. The apparent stress is calculated to be $2.4 \times 10^{-3} \mathrm{MPa}$.

\section{ROOF FALL EVENTS}

Four roof fall events are studied and in three of the cases the mine foreman verified the time and location of the roof fall. Two of the roof falls occurred on September 16, 2002, the third roof fall occurred on December 7, 2002, and the fourth roof fall occurred on December 4, 2003. The total volume of rock involved in the September 16 roof falls was estimated to be $2,150 \mathrm{~m}^{3}$ with a weight of approximately $5.7 \times 10^{6} \mathrm{~kg}$. This rockmass collapsed in two distinct events so the size and weight of the individual roof fall events could not be determined. The first fall occurred prior to a $4: 15$ am inspection of the area while the second fall occurred adjacent to the first and prior to a 1:30 pm inspection of this same area (Figure 8a). The third roof fall occurred at 10:24 am on December 7, involving approximately $900 \mathrm{~m}^{3}$ of rock and weighing close to $2.4 \times 10^{6} \mathrm{~kg}$ (Figure $8 \mathrm{~b}$ ). The fourth fall wasn't noticed by mine officials until the morning of December 5, 2003, but its prominent seismic record indicated that it occurred the day before at 5:05 pm. This roof fall is an extension of a previous fall (Figure $8 \mathrm{c}$ ) that enveloped a three-way intersection (Figure 8d).

Because these four roof falls were massive, they are wellrecorded by the seismic monitoring system. Three very distinctive events, occurring at 3:47 am and 11:14 am on September 16 and at 5:05 pm on December 4, are identified as the roof falls in question. In the case of the December 7 roof fall, a very distinctive seismic signature, occurring at the same time as the observed roof fall, was also available The automatic seismic monitoring system was triggered by these roof fall events. However, they were not automatically located due to the lack of distinct first arrivals. Figure 9 shows recordings from different geophones for each of the four roof fall events. In all examples, a prominent first arrival was not

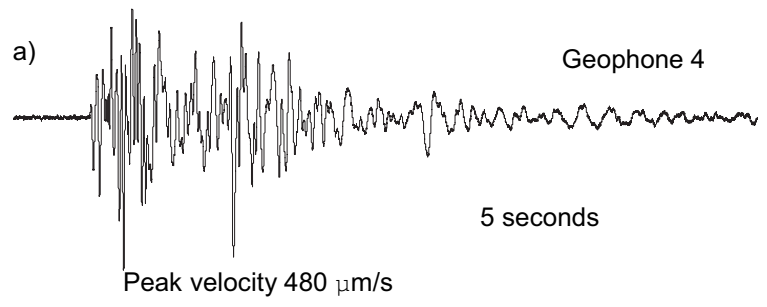

b)

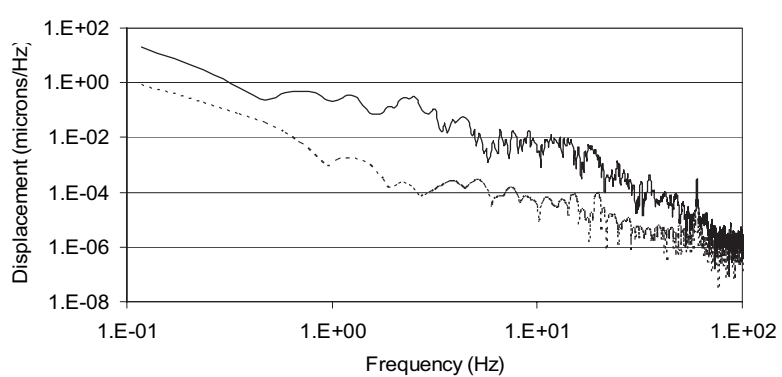

FIG. 7 Velocity waveform (a) recorded from a blast at the Rich Hill Quarry, $5.2 \mathrm{Km}$ from the seismic monitoring system. Corresponding Fourier displacement amplitude spectra (b), derived from 9 second duration windows including both $\mathrm{P}$ and $\mathrm{S}$ wave arrivals. Dashed lines indicate pre-P wave arrival noise levels 


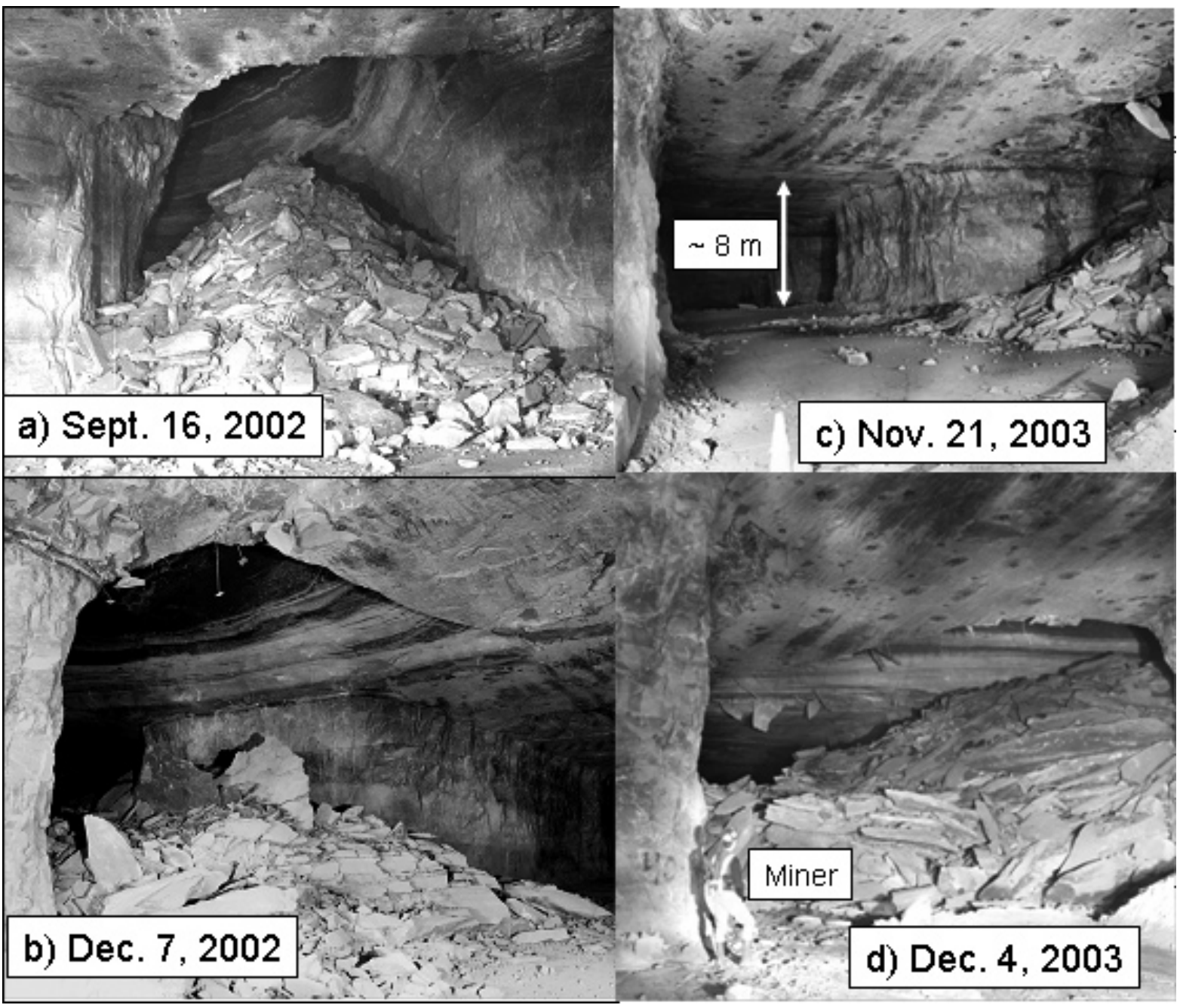

FIG. 8 Photographs of the material involved in the September 16 (a) and December 7, 2002 (b) events. Photograph (c) shows the mine entry prior to the December 4, 2003 roof fall extension event, while (d) shows the entry after the roof fall

recorded. A single roof fall event actually contains many individual rocks of varying size and shape striking the mine floor at slightly different times. Often, smaller rocks precede the bigger rocks, producing a kind of pre-fall rock dribble. This behaviour may produce emergent waveforms.

Multiple rocks striking the mine surface produce overlapping $P$ and $S$ signatures, which adds to the complexity of the signals. In addition, the vertical impulse of falling rocks produces Rayleigh surface waves. The September 16, 3:47 am event lasted for 6 seconds and contained several distinct clusters of higher amplitude waves. The signal started with a predominant frequency of $80 \mathrm{~Hz}$, gradually falling to $23 \mathrm{~Hz}$. The September 16, 11:14 am event lasted approximately 7 seconds, displaying four distinct bursts of energy. Initially, the frequency was $87 \mathrm{~Hz}$, dropping to 55 and then $12 \mathrm{~Hz}$. These distinct wave packets may be related to both the size and coupling of rocks impacting the mine floor. Rocks striking the clean mine floor at the initial stage of the event are effectively coupled and may produce signals with higher frequencies. As debris accumulates on the mine floor, the broken rock decouples the falling material. If enough debris is present or the falling rocks are small, this debris can absorb most of the fall's energy. This decoupling may contribute to a progressive lowering of wave frequencies during the roof fall episode. The December 7, 2002 and December 4, 2003 signals are much shorter in duration than the signals from the earlier roof fall events, lasting less than 4 seconds. They apparently occurred as single clusters of events and produced clearer

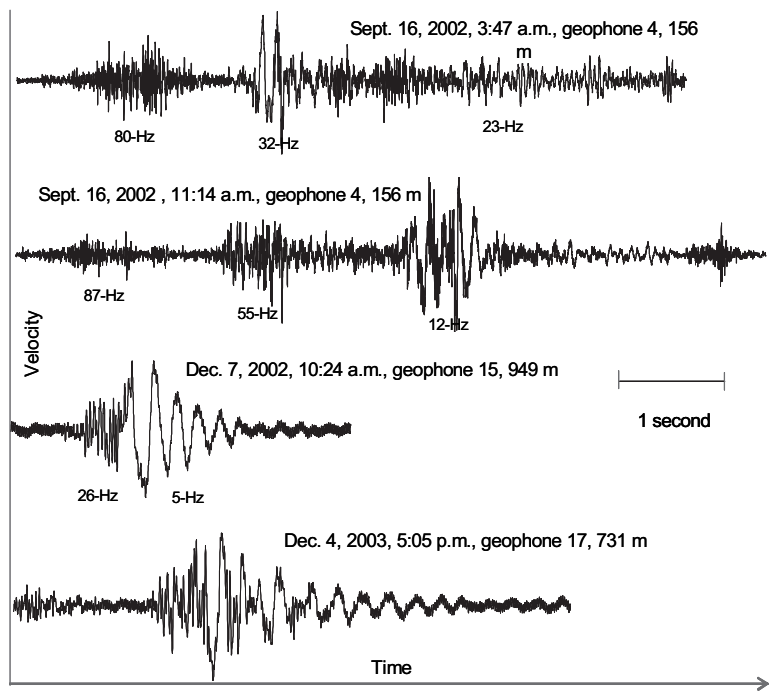

FIG. 9 Signals from 4 roof fall events. These events are complex, and in the case of the two events on September 16,2002 , involved multiple episodes of seismic energy release 


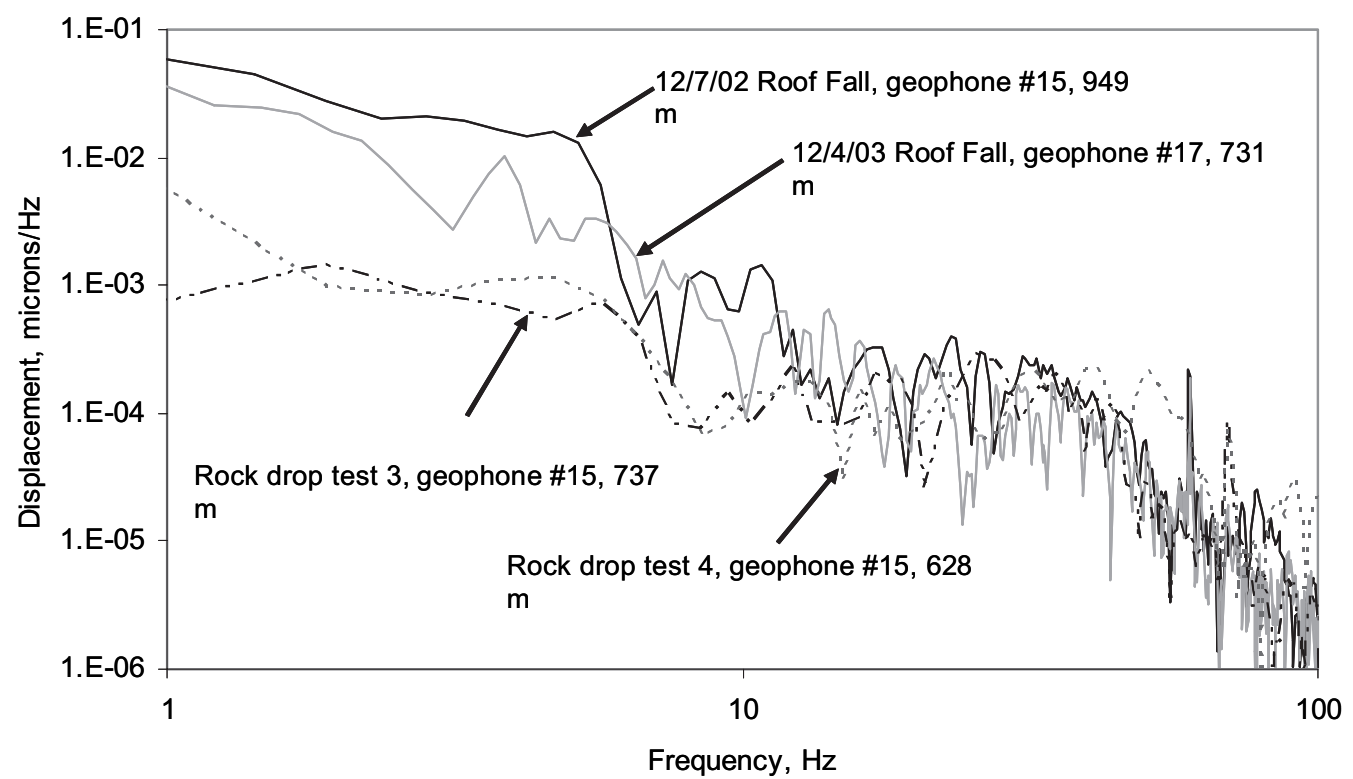

FIG. 10 Recorded Fourier displacement amplitude spectrum of two roof falls that are thought to have fallen as a mass within one distinct time period and two single rocks dropped from equivalent heights and similar distances from geophones

signals.

Figure 10 shows the recorded displacement amplitude spectra of the December 7, 2002 and December 4, 2003 roof falls at distances of 949 and $731 \mathrm{~m}$, respectively, compared to that of rock drop test number 3 and 4 recorded at 737 and $628 \mathrm{~m}$, respectively. The roof fall time series features a longer duration of the early, high-frequency part of the signal, followed by a large-amplitude, low-frequency, decaying sinusoidal component that is probably a Raleigh wave. The December 7, 2002 roof fall shows a much larger lowfrequency spectral level and a significant spectral minimum at approximately $7 \mathrm{~Hz}$. The recorded spectrum of rock drop test \#4 exceeds that of the roof fall at frequencies greater than $40 \mathrm{~Hz}$. Interpretation of a spectral corner frequency for the roof fall is ambiguous because it does not show a typical $\omega^{-2}$ shape.

Estimates of seismic moment of the four roof fall events range from $1.6 \times 10^{9}$ to $1.2 \times 10^{11} \mathrm{~N}-\mathrm{m}$ producing moment magnitudes ranging from 0.1 to 1.4 (Table 4). Radiated seismic energy is estimated to range from 7.7 to $631.3 \mathrm{~J}$. These values produce a range of apparent stresses from $3.4 \times 10^{-5}$ to $1.3 \times 10^{-4} \mathrm{MPa}$. The estimate of apparent stress, $\tau_{\mathrm{a}^{\prime}}$ for the roof fall is 2 to 14 times smaller than the values estimated for the five rock drop tests. Insofar as the rock drop tests involve apparent stresses in the low range for shear failure events at mines previously studied (McGarr, 1999), our observations here suggest the possibility that $\tau_{\mathrm{a}}$ may prove to be a useful parameter for discriminating various types of rock fall events from higher stress rock failures in the mining environment.

\section{ROCK FRACTURE EVENTS ASSOCIATED WITH ROOF FALLS}

A total of 35 small magnitude seismic events were recorded in the vicinity of the September 16 roof falls prior to collapse of the roof. Because most of these events were very small, they were usually recorded only by the closest five or six geophones. Figure 11 shows recordings from the largest of these rock fracture events, as well as a typical small event. These data were recorded by geophones attached to the roof, and exhibit $\mathrm{P}, \mathrm{S}$, and likely surface wave phases. The initial parts of the signals comprise high frequency body waves, followed by a sinusoidal component that is likely a Rayleigh wave. Figure 12 shows the Fourier displacement amplitude spectra for these same events. Estimates of seismic moment, moment magnitude, seismic energy, and apparent stress for the larger of the two events are $2.8 \times 10^{9} \mathrm{~N}-\mathrm{m}, 0.3,320 \mathrm{~J}$, and $1.8 \times 10^{-3} \mathrm{MPa}$, respectively. For the smaller of the two events seismic moment is $8.5 \times 10^{7} \mathrm{~N}-\mathrm{m}$, moment magnitude is -0.7 , seismic energy is $0.4 \mathrm{~J}$, and apparent stress is $6.7 \times 10^{-5} \mathrm{MPa}$. Moment magnitudes and seismic energies for 35 rock fracture events are shown in Figure 13.

Figure 13 provides an example of why monitoring mining-related seismic events and quantifying the sizes of those events are important. In general, the frequency of events increased closer to the occurrence of the massive roof falls of September 16. The number of events increased markedly within the six hour period preceding the first roof fall. The magnitudes of the 35 events are, in general, very small, averaging -0.9 with a standard deviation of 0.4 . The occurrence of one large "signature event" over one day prior to the roof fall tells much about the failure process. The roof fall occurs in response to an accumulation of relatively large

TABLE 4 Microseismic properties of roof fall events

\begin{tabular}{|c|c|c|c|c|c|c|c|c|c|c|}
\hline Date and Time & $\begin{array}{l}\text { Geophone } \\
\text { number }\end{array}$ & $\begin{array}{l}\text { Distance, } \\
\text { m }\end{array}$ & 凡o, $\mathrm{m} / \mathrm{Hz}$ & $\mathrm{Hz}$ range & $M_{0}, N-m$ & MM & $E_{s}$, Joules & $\mathrm{Hz}$ range & $\tau_{\mathrm{a}}, \mathrm{MPa}$ & $\begin{array}{l}\text { Duration, } \\
\text { s }\end{array}$ \\
\hline Sept. 16 3:47 am & 4 & 156 & $1.1 \times 10^{-8}$ & 1.1 to 400 & $1.6 \times 10^{9}$ & 0.1 & 7.7 & 1.1 to 400 & $7.7 \times 10^{-5}$ & 6 \\
\hline Sept. 16 11:14 am & 15 & 223 & $5.4 \times 10^{-7}$ & 1.1 to 80 & $1.2 \times 10^{11}$ & 1.4 & 631.1 & 1.1 to 80 & $8.8 \times 10^{-5}$ & 7 \\
\hline Dec. 7 10:24 am & 15 & 949 & $4.5 \times 10^{-8}$ & 1.4 to 105 & $4.2 \times 10^{10}$ & 1.1 & 336.0 & 1.4 to 105 & $1.3 \times 10^{-4}$ & 2.5 \\
\hline Dec. 4 5:05 pm & 17 & 731 & $2.6 \times 10^{-8}$ & 1.2 to 164 & $1.8 \times 10^{10}$ & 0.8 & 37.7 & 1.2 to 164 & $3.4 \times 10^{-5}$ & 3.5 \\
\hline
\end{tabular}



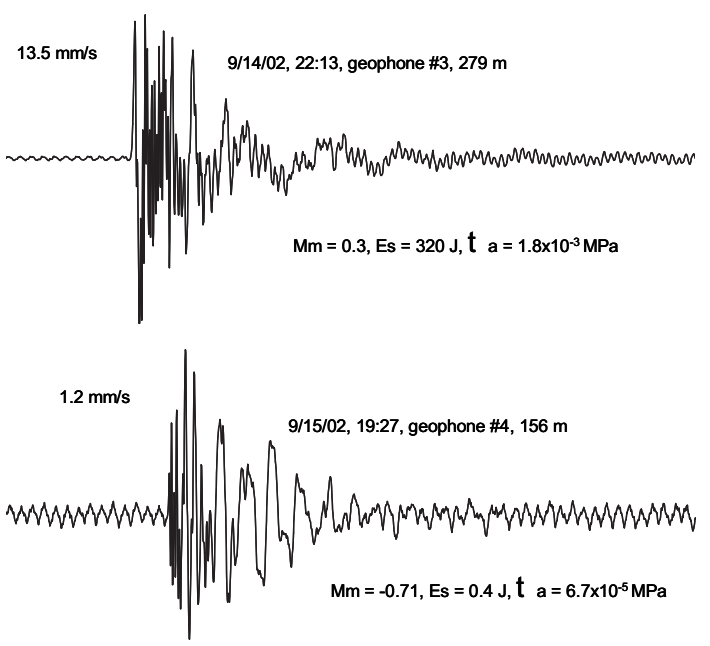

FIG. 11 Recorded waveforms for two rock fracture events that occurred in association with, but prior to the September 16, 2002 roof fall events. Traces (a) is from the larger of the two events while trace (b) is from a much smaller event. Time interval displayed equals one second and small fracture surfaces over a confined area as opposed to a large release of energy just prior to or in association with the roof fall.

Figure 14 summarizes the estimates of apparent stress for the various seismic sources examined in this study. The plot suggests that low apparent stress is a sensitive diagnostic for identifying seismic sources involving the failure and collapse of roof material. This study did not include sources that might be expected to produce high apparent stress, such as rock bursts or the faulting of intact rockmasses. Nevertheless, systematic determination of apparent stress may have general utility as a diagnostic for the highly variable failure mechanisms that occur in the mining environment and, in particular, with the rock fracture events that are associated with the roof falls. Roof fall events appear to be characterized by relatively low apparent stress, compared to other examples of mining induced seismicity previously reported. McGarr (1999) shows apparent stress values for natural earthquakes, mining induced earthquakes, laboratory stick-slip friction events, and earthquakes triggered by liquid injection fall in the range 0.001 to $10 \mathrm{MPa}$. With the exception of 3 of the 4 roof fall events, most of the other events studied here (rock

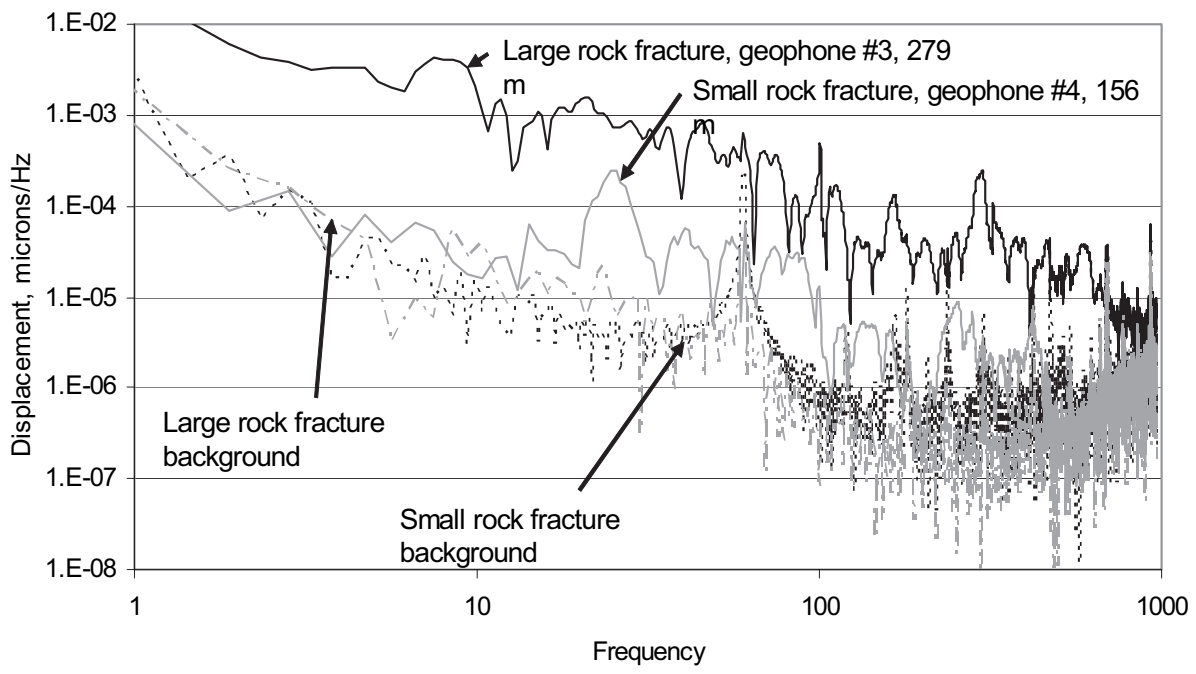

FIG. 12 Fourier displacement amplitude spectra of rock fracture events that occurred in association with, but prior to the September 16 , 2002 roof fall event (also see Figure 11)

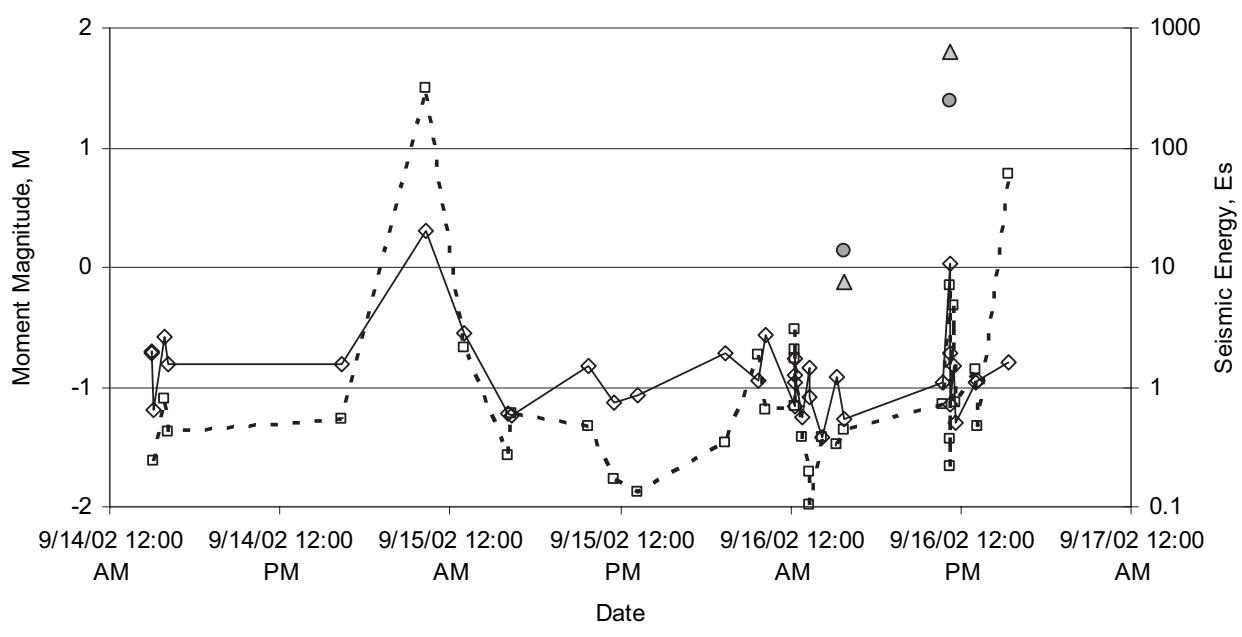

$\diamond$ Rock fractures, M $\bigcirc$ Rock falls, M - - - - Rock fractures, Es $\triangle$ Roof fall, Es

FIG. 13 Moment magnitude and seismic energy for rock fracture events associated with the September 16, 2002 roof fall events plotted versus time 


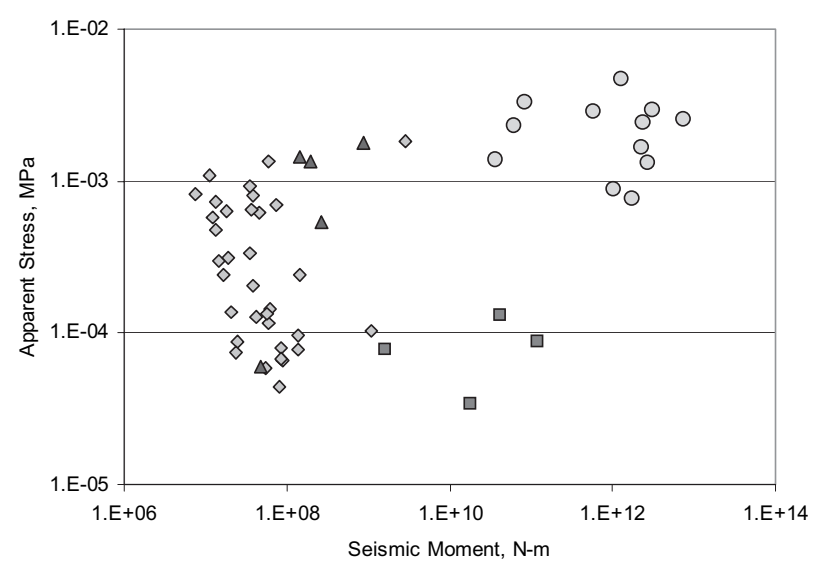

$\diamond$ Rock fractures $\square$ Roof falls $\Delta$ Drop tests o Blasts

FIG. 14 Base 10 logarithms of apparent stress versus seismic moment for events examined in this study

drops, rock fractures and the single blast example) fall within the low-stress part of this range, with values similar to those reported for earthquakes induced by fluid injection.

\section{SUMMARY AND CONCLUSIONS}

The purpose of the study is to test some analytical tools necessary to study the seismicity associated with roof fall events and the rock fracture events that occur in association with the roof falls. The seismic monitoring of these events is complicated by the fact that seismicity associated with roof falls may be of very low magnitude, and the roof fall events themselves show great variety and are extremely complex. Seismic moment, radiated seismic energy, and apparent stress are evaluated as tools useful in characterizing these events. To better calibrate this approach for the specific study site, the source parameters and necessary site specific properties such as $\mathrm{P}$ and $\mathrm{S}$ wave velocities were estimated from rock drop tests and quarry blasts, as well as the roof falls and associated small rock fracture events.

The diverse seismic sources examined at this mine yielded average apparent stress estimates in the relatively narrow range $1 \times 10^{-5}$ to $1 \times 10^{-2} \mathrm{MPa}$ for seismic moments in the range $1.1 \times 10^{7}$ to $7.6 \times 10^{12} \mathrm{~N}-\mathrm{m}$. Massive roof fall events, with seismic moments of $1.6 \times 10^{9}$ to $1.2 \times 10^{11} \mathrm{~N}$-m produced smaller apparent stresses ranging from $3.4 \times 10^{-5}$ to $1.3 \times 10^{-4} \mathrm{MPa}$. With the exception of the roof falls, the other events studied (single rock drops, blasts, small rock fractures) fall barely within the range of apparent stress $(0.001$ to $10 \mathrm{MPa})$ previously reported by McGarr (1999) for mining induced earthquakes, laboratory stick-slip friction events, earthquakes triggered by liquid injection and small earthquakes recorded in deep boreholes in California. The various events studied here have low apparent stress values similar to those reported for earthquakes induced by fluid injection.

The roof fall events are composite, comprising multiple impacts of rocks of varying size on the mine floor. Eight rock drop tests demonstrate that the roof falls are very inefficient sources of high frequency seismic energy, primarily because the accumulation of debris on the mine floor decouples the transfer of kinetic energy from the falling mass to the ground. Also, kinetic energy to seismic energy transfer in the case of single falling rocks appears to be inherently inefficient, even under ideal conditions. Five rock drops onto a clear, hard limestone floor resulted in an average ratio of radiated to seismic kinetic energy of approximately $4 \times 10^{-5} \mathrm{~J}$. Hence, seismic monitoring of small roof fall events requires that instruments be placed at small distances from the anticipated source area.

Seismic monitoring with carefully calibrated instruments and analysis procedures can be an important tool for assessing the stability of mine roof strata. This study observed that roof falls occur in conjunction with very small seismic events that are referred to above as "rock fractures". These events range in magnitude from about -1.4, the limit of our detection system, to 0.3 . The roof failed in response to an accumulation of one moderately large and many relatively small fracture events occurring in a confined area that had been seismically active for months. The main collapse appears to be the result of a gradual increase in fracture density over a long period of time and did not occur in association with a sudden, major release of strain energy. The precursory nature of the small rock fracture events in connection with the associated roof falls is an important observation that demands additional research. Because the roof falls are characterized by unusually low apparent stress and moderate moment magnitudes, compared to previously reported results for mining induced seismicity, they appear to represent a new class of mining induced event that occurs in stratified rock units. Successful monitoring programs must deal with the small seismic energy levels associated with these events. While it is the roof falls that most impact the safety of miners, it is the rock fracture events that may help us to anticipate areas of unstable roof.

\section{REFERENCES}

Aki, K. (1968) Seismic Displacements Near a Fault. Journal of Geophysical Research, 73, 5359-5376.

Boatwright, J. and Fletcher, J. B. (1984) The Partition of Radiated Seismic Energy Between P and S Waves, Bull. Seism. Soc. Am., 74, 361-376.

Boore, D.M. and Boatwright, J. (1984) Average Body-Wave Radiation Coefficients, Bull. Seismol. Soc. Am. 74, 1615-1621.

Ellenberger, J.L., Heasley, K.A., Swanson P.L. and Mercier, J. (2001) Three Dimensional Microseismic Monitoring of a Utah Longwall, Proc. Of the 38th U.S. Rock Mechanics Symp., Washington, D.C., July 7-10, 2001, pp.1321-1326.

Ferriter, R.L., Zipf, R.K., Ropchan, D.M. and Davidson, J. (1995) Fatal Mine Collapse Accident - the Solvay Mine, Technical Investigation Report, Underground Nonmetal Mine, Feb. 3, 1995, Denver Safety and Health Technology Center, MSHA, pp. 58.

Hanks, T. and Kanamori, H. (1979) A Moment Magnitude Scale. Journal of Geophysical Research, 84, 2348-2350.

Hatherly, P., Gale, W., Medhurst, T., King, A., Craig, S., Poulsen, B. and Luo, X. (2003) 3D Stress Effects, Rock Damage and Longwall Caving as Revealed by Microseismic Monitoring, ACARP Project C9021, Exploration and Mining Report 1008F, March 2003, pp. 178.

Iannacchione, A.T. and Zelanko, J.C. (1995) Occurrence and Remediation of Coal Mine Bumps: A Historical Review, in Mechanics and Mitigation of Violent Failure in Coal and Hard-Rock Mines, U.S. Bureau of Mines Special Publication SP 01-95, 1995, pp. 27-67.

Iannacchione, A.T. and Coyle, P. (2002) An Examination of the Loyalhanna Limestone's Structural Features and Their Impact on Mining and Ground Control Practices, 21st Intern. Conf. on Ground Control in Mining, Morgantown, WV, Aug. 6-8, 2002, pp. 218-227.

Iannacchione, A.T., Marshall, T.E., Burke, L., Melville, R. and Litsenberger, J. (2003) Safer Mine Layouts for Underground Stone Mines Subjected to Excessive Levels of Horizontal Stress, Mining Engineering, April 2003, pp. 25-31.

Kusznir, N.J., Al-Saigh, N.H. and Ashwin, D.P. (1984) Induced Seismicity Generated by Longwall Coal Mining in the North Staffordshire Coal-Field, U.K., Proc. of the 1st Intern. Congress on Rockbursts and Seismicity in Mines, Johannesburg, 1982, pp. 153-160.

McGarr, A. (1999) On Relating Apparent Stress to the Stress Causing Earthquake fault slip. Journal of Geophysical Research, B, Solid Earth and Planets, Vol. 104, No. 2, February 10, 1999, pp. 3003-3011.

Philllips, W.S., Pearson, D.C., Edwards, C.L. and Stump, B.W. (1997) Microseismicity Induced by a Controlled Mine Collapse at White Pine, Michigan, Intern. Journal of Rock Mechanics and Mining Science, Vol. 34, No. 3-4.

Redmayne, D.W. (1988) Mining Induced Seismicity in UK Coalfields Identified on the BGS National Seismograph Network, Engineering Geology of Underground Movements, Engineering Geology Special Publication No. 5, pp. 405-413. 
Swanson, P.L. and Boler, F.M. (1995) The Magnitude 5.3 Seismic Event and Collapse of the Solvay Trona Mine: Analysis of Pillar/Floor Failure Stability, U.S. Bureau of Mines Open File Report 86-95, pp. 82.

Westbrook, G.K., Kusznir, N.J., Browitt, C.W.A. and Holdsworth, B.K.

(1980) Seismicity Induced by Coal Mining in Stoke-on-Trent (U.K.),

Engineering Geology, 16, Elsevier Co., Amsterdam, pp. 225-241.

Wyss, M. (1970) Stress Estimates for South American Shallow and Deep

Earthquakes, Journal of Geophysical Research, Vol. 75, 1529-1544. 